Revista Latinoamericana de la Papa 19 (1): 1-17

ISSN: 1853-4961

http://www.papaslatinas.org/revista.html

\title{
Comportamiento de la actividad alimentaria y de oviposición de Liriomyza huidobrensis (Blanchard) (Diptera: Agromyzidae), en variedades de Solanum tuberosum L.
}

\author{
R. A. López ${ }^{1 / *}$; D. Carmona ${ }^{2}$; E. Trumper ${ }^{3}$; M. Huarte ${ }^{2}$
}

Manuscrito recibido: $21 / 10 / 2014$

Aceptado: 14/04/2015

Disponible en línea: Junio 2015

\section{Resumen}

En el sudeste de la provincia de Buenos Aires, República Argentina, se han registrado ataques de la "mosca minadora de las hojas", Liriomyza huidobrensis (Blanchard), en el cultivo de papa desde la década del '90, con daños económicamente significativos, por lo que se la considera plaga principal. Hay evidencias que muestran diferencias de intensidad de daño entre variedades de papa y entre estratos del follaje, sin contar con información relacionada al comportamiento de la plaga. En este contexto, se estudiaron los efectos de los estratos y variedades de papa sobre la preferencia alimentaria y de oviposición de L. huidobrensis. Se realizaron muestreos semanales en parcelas bajo infestación natural, artificial y en condiciones controladas en las variedades Shepody, Frital, Innovator, Daisy y Russet Burbank, distribuidas en un diseño en parcelas divididas con tres repeticiones. Para las evaluaciones se establecieron tres estratos en la planta: estrato basal $(0-20 \mathrm{~cm})$, estrato medio $(20-40 \mathrm{~cm}$ ) y estrato superior (mas de $40 \mathrm{~cm}$ ). En cada estrato se muestrearon los foliolos y se cuantificó el número de punciones alimenticias y de huevos, variables indicadoras de preferencia alimentaria y de oviposición, respectivamente. Las hembras de L. huidobrensis realizaron mayor número de picaduras de alimentación y colocaron mayor número de huevos en las hojas del estrato basal en comparación al estrato medio y superior. Las variedades Daisy y Russet fueron las que presentaron el menor número de huevos y picaduras de alimentación en comparación con Shepody, Innovator y Frital durante todo el monitoreo.

Palabras clave adicionales: Preferencia, variedades papa, picaduras de alimentación, picaduras de oviposición.

\section{Behavior of Liriomyza huidobrensis (Blanchard) (Diptera: Agromyzidae) on varieties of Solanum tuberosum L.}

\section{Summary}

In the southeast of Buenos Aires province were recorded attacks of "leafminer leaves", Liriomyza huidobrensis (Blanchard), to potato crop since the 90s, and because of the economics damage produced, from potential pests become major pest of the crop. Background studies showed damage intensity differences between potato varieties and between layers of foliage, with this history we proposed study the effects of the layers and potato varieties on food and oviposition preference of $L$. huidobrensis. Weekly samplings were conducted on plots under natural, artificial and controlled conditions of infestation on Shepody, Frital, Innovator, Daisy and Russet Burbank varieties, distributed in a split plot

\footnotetext{
Autor para correspondencia. Correo electrónico: rafael.1.lopez@ monsanto.com.

Facultad de Ciencia Agrarias, Universidad Nacional de Mar del Plata, Argentina.

2 Instituto Nacional de Tecnología Agropecuaria, Balcarce - Facultad de Ciencia Agrarias, Universidad Nacional de Mar del Plata, Argentina.

Instituto Nacional de Tecnología Agropecuaria, Manfredi.
} 
design with three replications. For assessments, three layers were established in the plant: basal layer $(0-20 \mathrm{~cm})$, middle layer $(20-40 \mathrm{~cm})$ and upper layer $($ over $40 \mathrm{~cm})$. In each layer the leaflets were sampled and the number of feeding punctures and egg, indicators of feeding and oviposition preference respectively, were quantified. Females of $L$. huidobrensis performed higher number of feeding punctures and placed higher number of eggs on the leaves of the basal layer compared to the middle and upper layers. Daisy and Russet varieties were those that showed the lowest number of eggs and feeding punctures compared to Shepody, Innovator and Frital throughout the monitoring.

Additional keywords: Preference, potato varieties, feeding punctures, oviposition punctures.

\section{Introducción}

La "mosca minadora de las hojas", Liriomyza huidobrensis, Blanchard es considerada una plaga de importancia económica en la producción de papa a nivel mundial, por los daños directos que ocasiona, y por la persistencia de sus poblaciones en el cultivo, a pesar de la utilización excesiva de insecticidas (Weintraub y Horowitz, 1995). En Argentina, se ha registrado su presencia en las provincias de Buenos Aires, Córdoba, Tucumán y Jujuy, en una gama de hospederos cultivados y en vegetación espontánea, que le permite llevar a cabo sus ciclos biológicos sin limitaciones de alimentos y refugios (Valladares et al., 1996). En el sudeste de la Provincia de Buenos Aires, la principal zona productora de papa en verano, en los últimos 20 años se han registrado ataques de $L$. huidobrensis ocasionando en algunos casos, la pérdida total del cultivo (López et al., 2010). El uso excesivo de insecticidas ha ocasionado la disminución de los enemigos naturales y la desregulación de la plaga, la cual pasó a considerarse plaga principal del cultivo (Cambareri, 2004; Vincini y Carmona, 2006).

Dada esta situación, para dicha zona se han llevado a cabo estudios sobre la fluctuación poblacional de adultos de $L$. huidobrensis, se han caracterizado los distintos tipos de daño con relación al desarrollo del cultivo de papa, y se ha determinado el Nivel de Daño Económico (Cambareri, 2004; Carmona y López, 2007; Carmona y Caldiz, 2003; López, 2008 y López et al., 2010). Se ha determinado una asociación entre la variación de la abundancia de adultos, los estados inmaduros de L. huidobrensis y el desarrollo del cultivo de papa, con un incremento relativamente lento de la densidad poblacional de la plaga durante el crecimiento vegetativo del cultivo, seguido de un incremento sostenido durante el período de tuberización - floración (Cambareri, 2004). López et al. (2010) determinaron el grado de daño en siete variedades de papa para industria, y hallaron diferencias de comportamiento ante el daño de $L$. huidobrensis, conformando dos grupos con diferente severidad de daño. En las variedades Shepody, Kennebec, Frital e Innovator el grado de daño moderado (40 a $60 \%$ del área foliar dañada) alcanzó el estrato medio entre los 70 y 80 días desde la plantación, mientras que las variedades Santana, Russet Burbank y Ranger Russet presentaron un comportamiento similar, con la manifestación del grado de daño moderado en el estrato medio aproximadamente 15 días más tarde. El daño siguió su evolución gradualmente hasta alcanzar la máxima severidad hacia el final de la estación, siendo mayor en las variedades Shepody, Kennebec, Frital e Innovator con respecto a Santana, Ranger Russet y Russet Burbank ( López et al., 2010).

En cuanto a los daños manifestados como "picaduras" y "minas", se determinó una distribución vertical diferencial en el follaje del cultivo, presentando mayor grado de daño el estrato inferior $(0-20 \mathrm{~cm})$ durante los primeros estadios de 
crecimiento vegetativo del cultivo, para luego avanzar hacia los estratos medio (20$40 \mathrm{~cm}$ ) y superior (40 cm hasta extremo superior de la planta) al comienzo de la floración del cultivo (Cambareri, 2004; López et al., 2010). Los daños visibles provocados por las picaduras $\mathrm{y}$ especialmente por las "minas" producidas por las larvas, constituyen un índice confiable del nivel de abundancia de la "mosca minadora de la hoja". Sin embargo, existen muchas causas que pueden explicar las diferencias de daños identificadas entre variedades $y$ entre estratos dentro del follaje de una misma planta.

Debido a que la larva de L. huidobrensis se alimenta dentro del folíolo y completa su desarrollo allí mismo, la elección de su hábitat y alimento esta dada por la hembra al momento de oviponer. Esta decisión sobre el sitio de oviposición depende de tres factores principales: la adecuación de la planta hospedera, la presencia o ausencia de otros organismos fitófagos $\mathrm{o}$ fitopatógenos y la presencia de enemigos naturales (Videla et al., 2006). La adecuación de la planta hospedera está basada tanto en factores cuantitativos, como el tamaño y la posición de las hojas, espesor de los folíolos, barreras mecánicas y niveles de nutrientes; como en factores cualitativos, composición cuticular, aleloquímicos específicos y cambios fenológicos (Faeth, 1985). Todos estos factores varían sustancialmente dentro y entre plantas, y dichas variaciones tienen una influencia significativa en la eficiencia de la alimentación de los insectos (Kimmerer y Potter, 1987; Suomela y Nilson, 1994; Fisher et al., 2000). Otros individuos fitófagos pueden generar competencia intraespecífica y/o interespecífica. La presencia o actividad de individuos conespecíficos es uno de los factores externos que puede influir en la selección de las plantas hospedadoras. La preferencia puede también variar como consecuencia de la experiencia previa obtenida por los estados inmaduros en una determinada especie de planta hospedadora (Bernays y Chapman, 1994). La experiencia previa como adulto, independientemente de la obtenida como larva, puede también alterar los patrones de selección del hospedero (Boller et al., 1998; McNeely y Singer, 2001; Solarz y Newman, 2001).

En este estudio se plantea como objetivo evaluar la preferencia de alimentación y oviposición de los adultos de $L$. huidobrensis por distintas variedades de papa y estratos del follaje.

\section{Materiales y Métodos}

Patrón de disposición de L . huidobrensis en la planta. Se realizaron muestreos semanales (durante ocho semanas) en dos predios experimentales ubicados en los partidos de General Alvarado, $38^{\circ} 9^{\prime} 21^{\prime \prime} \mathrm{S}, 58^{\circ} 1^{\prime} 42^{\prime \prime} \mathrm{W}$ (ciclo agrícola 2008/2009) y Balcarce, 37 $49^{\prime} 00^{\prime \prime} \mathrm{S}$ $58^{\circ} 15^{\prime} 00^{\prime \prime} \mathrm{O}$ (ciclo agrícola 2009/2010), sudeste de la provincia de Buenos Aires, Argentina, ambos cultivados con las variedades Shepody, Frital, Innovator, Daisy y Russet Burbank. Las mismas se establecieron en un diseño en Parcelas Divididas con tres repeticiones; cada unidad experimental correspondió a una parcela de $6 \times 6 \mathrm{~m}$. La plantación se realizó el 18 y el 15 de noviembre en el primer y segundo ciclo productivo, respectivamente, a una distancia entre hileras de $80 \mathrm{~cm}$ y a una densidad de 4 "cortes" $/ \mathrm{m}^{2}$ (reproducción vegetativa mediante trozos de tubérculos). Se establecieron tres estratos en la planta: basal $(0-20 \mathrm{~cm})$, medio $(20-40 \mathrm{~cm})$ y superior $(\mathrm{de} 40 \mathrm{~cm}$ al extremo superior de la planta), de los cuales se colectaron 3 folíolos al azar, totalizando 9 folíolos por unidad experimental. En el laboratorio de Investigación y Servicios en Zoología Agrícola de la UI EEA Balcarce, INTAFCA, UNMdP, se analizaron los folíolos y se cuantificó el número de "picaduras de alimentación" o punciones alimenticias y 
de “oviposición" por $\mathrm{cm}^{2}$, variables indicadoras de preferencia alimentaria y de oviposición, respectivamente (Parrella y Bethke, 1984; Videla et al., 2006). Se evaluaron 360 folíolos por ciclo agrícola. Los datos fueron analizados con modelos lineales generales y mixtos, con comparación de medias a través de LSD, utilizando el paquete estadístico INFOSTAT (Di Rienzo et al., 2013).

Prueba de preferencia sin elección en el campo. Durante el período de tuberización del cultivo (aproximadamente 80 días desde la plantación), en una planta de cada variedad, se colocaron tres hembras fecundadas de L. huidobrensis, obtenidas de la cría en laboratorio. Las plantas fueron cubiertas en el campo por una jaula de estructura de hierro y paredes de voile, para evitar el escape de los individuos adultos y excluir otros individuos. Se estableció un diseño completamente aleatorizado con tres repeticiones, con individuos diferentes en cada una de ellas para evitar la pseudoreplicación.

Luego de su exposición a las moscas durante $24 \mathrm{hs}$, las hojas fueron observadas con microscopio estereoscópico Olympus $160 \mathrm{x}, \mathrm{y}$ se cuantificó el número de punciones alimenticias y de huevos. Se observaron 135 folíolos por cada ciclo agrícola.

Los datos fueron analizados con modelos lineales generales y mixtos, con comparación de medias a través de LSD, utilizando el paquete estadístico INFOSTAT (Di Rienzo et al., 2013).

Efectos de la experiencia previa sobre la preferencia. Se seleccionaron dos cultivos comerciales, uno de la variedad Innovator y otro con la variedad Spunta. Se asumió que las "moscas minadoras" presentes en dichos cultivos tendrían experiencia previa como larvas y adultos sólo en las variedades allí plantadas. En cada cultivo se colocaron tres plantas de cada variedad a evaluar (Shepody, Innovator, Daisy, Frital y Russet Burbank), producidas en macetas (una planta por maceta), y distribuídas aleatoriamente en tres bloques, conteniendo cada uno las cinco variedades, a modo de repeticiones. Todas las plantas (cultivo y en macetas) estuvieron en el estado fenológico de tuberización. Luego de permanecer siete días en el campo, las plantas en macetas fueron llevadas al laboratorio y mediante microscopio estereoscópico Olympus 160 x se cuantificó el número de punciones alimenticias y de huevos (Parrella y Bethke, 1984) en cada variedad. Se analizaron 45 folíolos por cada ciclo agrícola. Los datos fueron analizados con modelos lineales generales y mixtos, con comparación de medias a través de LSD, utilizando el paquete estadístico INFOSTAT (Di Rienzo et al., 2013).

Test de preferencia en el Laboratorio. Macetas con plantas de las cinco variedades evaluadas (una planta por maceta), fueron establecidas en un diseño completamente aleatorizado con tres repeticiones, en cámara de cría a $20{ }^{\circ} \mathrm{C}( \pm$ $\left.2^{\circ}\right)$ y un fotoperíodo de 12L:12O. La plantas fueron expuestas simultáneamente a 15 hembras fecundadas de $L$. huidobrensis por 24 horas, y cubiertas con una jaula de estructura de hierro y paredes de tela de voile. Para cada planta se determinó: 1) densidad de punciones de alimentación (número de punciones por $\mathrm{cm}^{2}$ de área foliar), variable que indica preferencia alimentaria; 2) densidad de huevos viables (número de minas por $\mathrm{cm}^{2}$ de área foliar) variable que indica preferencia de oviposición.

Los datos fueron analizados con modelos lineales generales y mixtos, con comparación de medias a través de LSD, utilizando el paquete estadístico INFOSTAT (Di Rienzo et al., 2013).

\section{Resultados y Discusión}

Preferencia alimentaria entre variedades. Las variedades Shepody, 
Frital e Innovator presentaron mayor número de punciones de alimentación, en promedio de todos sus estratos, en comparación con Daisy y Russet Burbank (Figura 1), indicando la preferencia de $L$. huidobrensis por dichas variedades para alimentarse. La misma tendencia se repite en ambos ciclos agrícolas, si bien durante el ciclo 2009/2010, el número de picaduras fue significativamente menor (Figura 1).

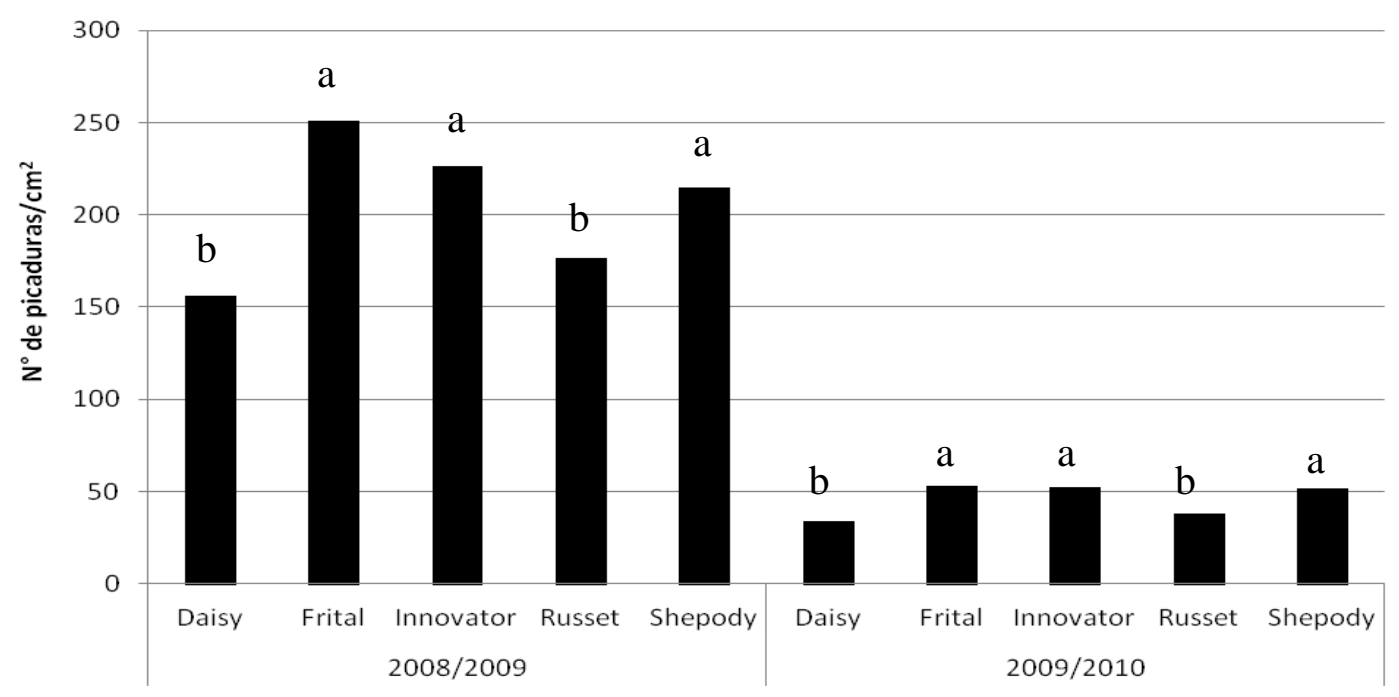

Figura 1. Número de picaduras de alimentación $/ \mathrm{cm}^{2}$ en pruebas de libre elección, promedio de todos los estratos de la planta, por cada variedad y ciclo agrícola. Medias con una letra común no son significativamente diferentes $(\mathrm{p}<=0,05)$.

Las variedades Shepody, Frital e Innovator fueron las más preferidas para oviponer, con relación a Daisy y Russet. La misma tendencia se repitió en ambos ciclos agrícolas (Figura2).

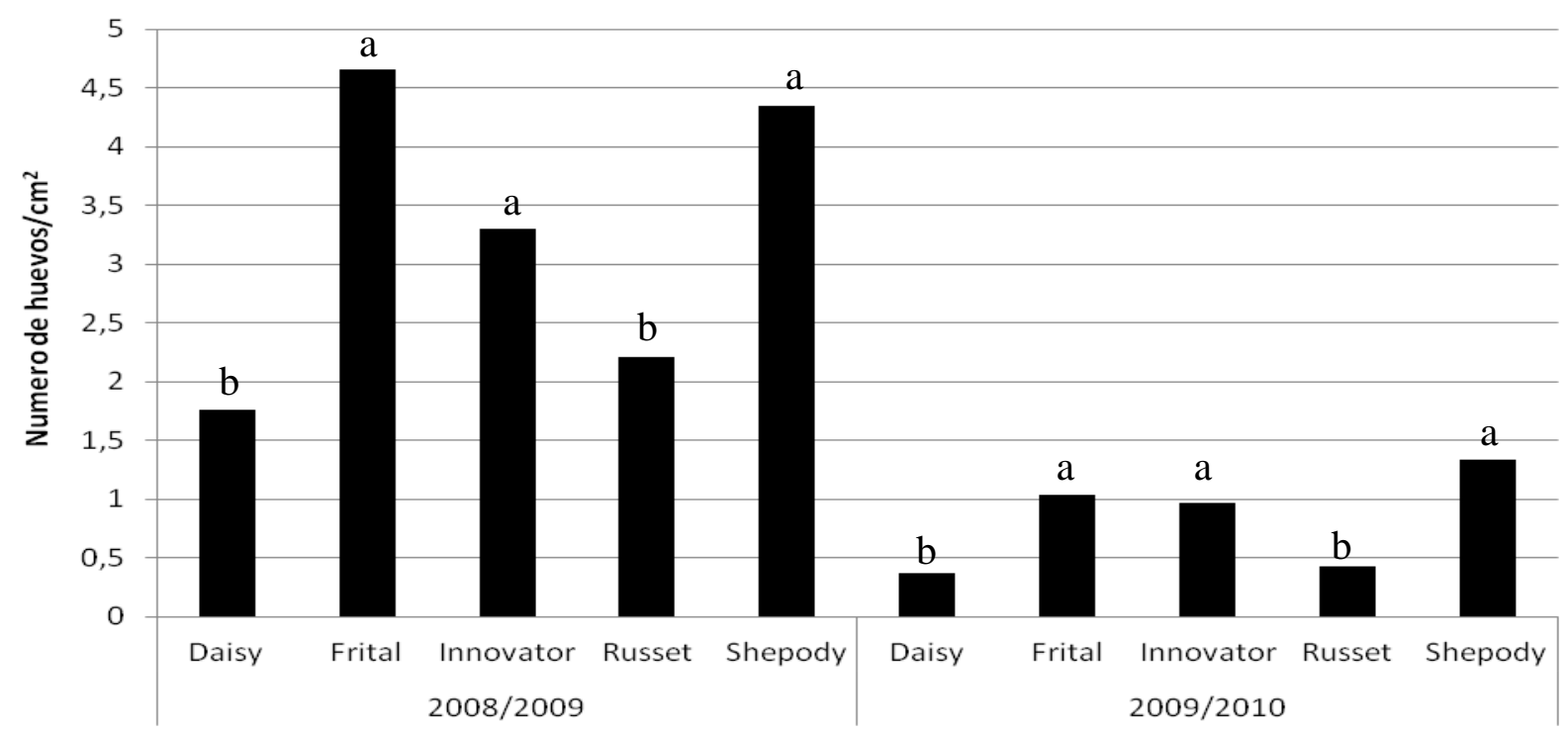

Figura 2. Número de picaduras de oviposición $/ \mathrm{cm}^{2}$ en pruebas de libre elección, promedio de todos los estratos de la planta, por cada variedad y ciclo agrícola. Medias con una letra común no son significativamente diferentes $(\mathrm{p}<=0,05)$. 
Revista Latinoamericana de la Papa 19 (1): 1-17

http://www.papaslatinas.org/revista.html

Las variedades Daisy y Russet fueron las que presentaron el menor número de picaduras de alimentación y de oviposición, durante todo el período de evaluación. Consecuentemente, estas variedades fueron las que menos daño presentaron. Este resultado coincide con trabajos previos (López et al., 2010), en el que las evaluaciones en cultivos de papa a campo, diferenciaron a las variedades Daisy y Russet como las menos dañadas y a las variedades Shepody, Frital e Innovator como las más dañadas. Si bien se utilizó una metodología de evaluación menos minuciosa que la del presente estudio, se arribó a resultados similares, con lo cual se infiere que el método de monitoreo utilizado en el campo es eficiente y puede servir para determinar en forma rápida el daño realizado por la plaga (López et al., 2010).

Esta preferencia diferencial entre variedades se halla documentada para el género Liriomyza en diferentes especies vegetales (Avalos et al., 2013; Martin et al., 2005; Weigand, 1990). Las características morfologicas podrían estar explicando estas diferencias; quizás Daisy y Russet presentan una mayor densidad de tricomas en sus folíolos y/o que éstos sean de tipo glandular como los encontrados por Bernays y Chapman (1994) en Solanum berthaultii. Dichos tricomas al romperse liberan una sustancia cementante que inmoviliza a los insectos en la superficie foliar, impidiéndoles alimentarse. Otra variable, como el tamaño de los folíolos, probablemente hace que sean menos preferidos por las hembras al momento de oviponer, por ser de menor tamaño.

Analizando específicamente las picaduras de alimentación (preferencia alimentaria), se observó una marcada preferencia por el estrato basal y medio de la planta en todas las variedades evaluadas, siendo el estrato superior menos preferido por Liriomyza para alimentarse. Es de destacar que durante el ciclo 2009/2010, el número de picaduras fue menor con respecto del ciclo 2008/2009, manteniéndose de todos modos la tendencia de estratificación de la preferencia alimentaria. Todas las diferencias antes descriptas fueron estadísticamente significativas (Figura 3).

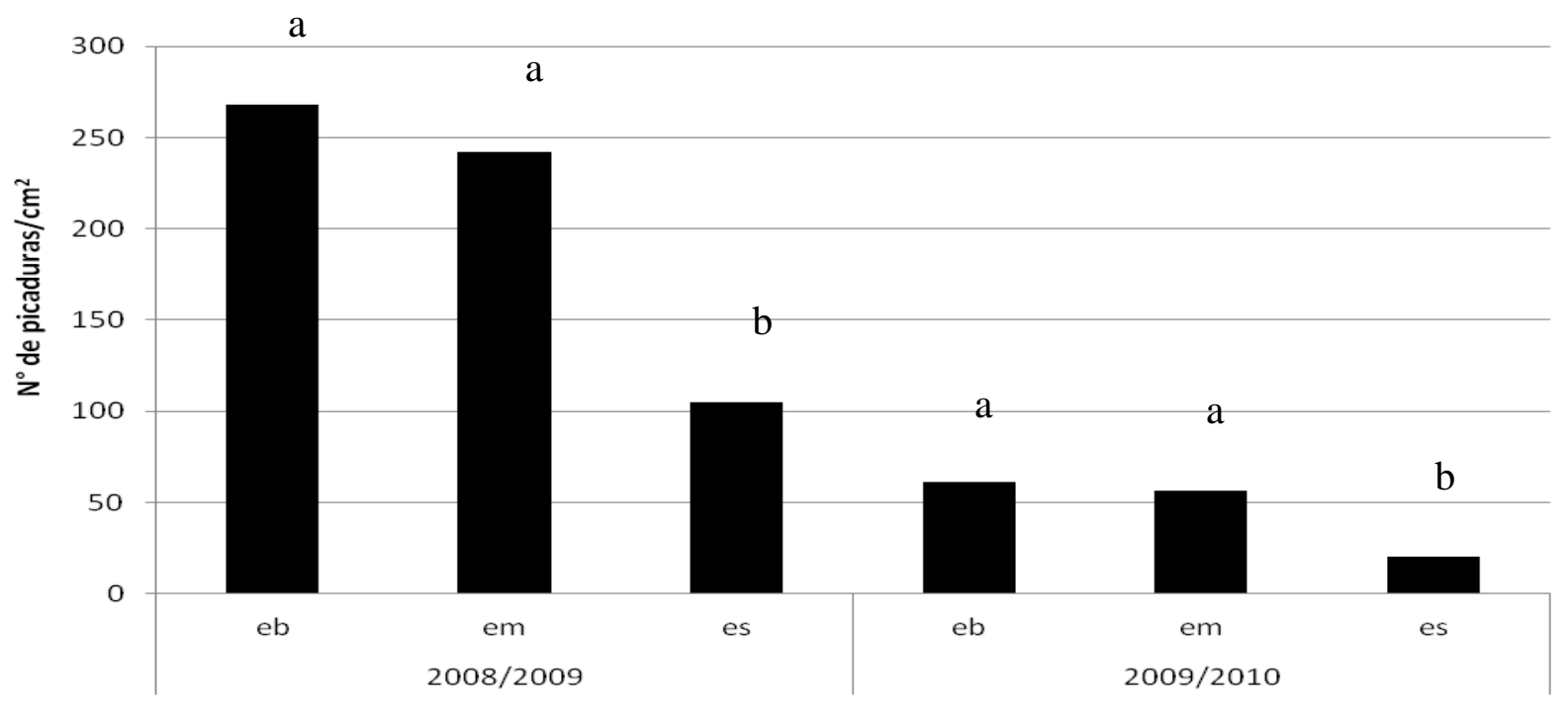

Figura 3. Número promedio de picaduras de alimentación $/ \mathrm{cm}^{2}$ en pruebas de libre elección, sobre los estratos basal (eb), medio (em) y superior (es); para todas las variedades analizadas en cada ciclo agricola. Medias con una letra común no son significativamente diferentes $(\mathrm{p}<=0,05)$. 
En cuanto a picaduras de oviposicion (preferencia de oviposición), se observó una tendencia similar a la de preferencia alimentaria, aunque en éste caso se diferenciaron significativamente los tres estratos entre sí, presentando, en orden decreciente, el estrato inferior la mayor preferencia, respecto del estrato medio y del estrato superior. La tendencia es similar en ambos ciclos agrícolas evaluados (Figura

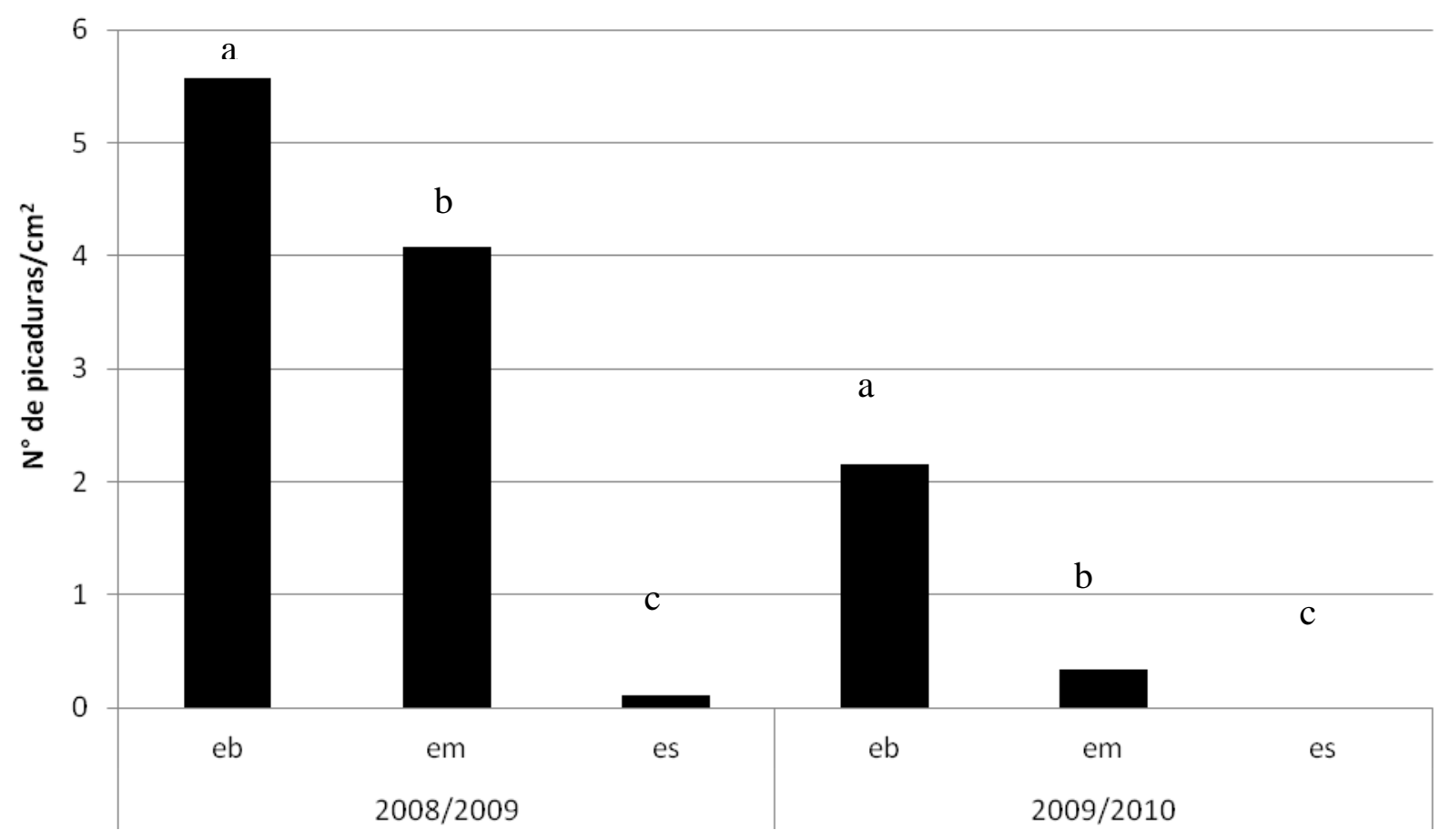

Figura 4. Número promedio de picaduras de oviposición $/ \mathrm{cm}^{2}$ en pruebas de libre elección, sobre los estratos basal (eb), medio (em) y superior (es); para todas las variedades analizadas en cada ciclo agrícola. Medias con una letra común no son significativamente diferentes $(\mathrm{p}<=0,05)$.

Esto indica una clara preferencia de $L$. huidobrensis por las hojas de mayor edad en la planta para alimentarse y oviponer. Esta preferencia fue más marcada al momento de oviponer, ya que el número de picaduras de oviposición fue significativamente diferente entre todos los estratos, siendo el estrato basal el más preferido. Respecto de las picaduras de alimentación, dada la distribución registrada en los estratos de la planta, se deduce que la hembra prefiere en igual magnitud al estrato medio y basal para alimentarse.

Las hojas mas jóvenes ofrecen menor área para que los adultos se alimenten $\mathrm{y}$ ovipongan, y además menos alimento y espacio para las larvas (Facknath, 2005). Otro factor de incidencia es el número de tricomas, los cuales permanecen constantes en cada folíolo, pero a medida que la hoja se expande, la densidad de tricomas con relación a la superficie disminuye con la edad (Fagoonee y Toory, 1983). La mayor superficie foliar y la menor densidad de tricomas en las hojas del estrato basal podrían ser los factores determinantes de la preferencia de L. huidobrensis.

Los tricomas impiden el movimiento de los adultos en las hojas e interfieren con la alimentación y oviposición, generándose una correlación estrecha y negativa entre 
preferencia y densidad de tricomas ( $\mathrm{Li}$ et al., 2003). La preferencia exhibida por los adultos de Liriomyza hacia el estrato basal en este trabajo coincide con lo encontrado por Neder de Román et al. (1993) en habas y por Gómez y Rodríguez (1994) en papa. Otros autores no encontraron estas diferencias entre estratos, pero evaluaron la preferencia como la proporción de picaduras de oviposicion sobre el total de picaduras. La utilización de esta metodología estaría sustentada por el patrón de distribución de picaduras no aleatorio (Martin et al., 2005)

\section{Prueba de preferencia sin elección a campo.}

Se observaron diferencias en el número total de picaduras de alimentación entre variedades, siendo Daisy y Russet las que presentaron menor número en los dos ciclos agrícolas evaluados. Las variedades con mayor número de picaduras de alimentación fueron Shepody y Frital durante los dos ciclos agrícolas evaluados. La variedad Innovator tuvo un comportamiento intermedio, ya que durante el primer ciclo presentó mayor número de picaduras que Daisy y Russet, pero menor número de picaduras que Shepody y Frital. En cambio, en el segundo ciclo presentó un número de picaduras similar a Shepody y Frital (Tabla

Tabla 1. Número de picaduras de alimentación y oviposición por $\mathrm{cm}^{2}$ en pruebas sin elección a campo (promedio de toda la planta) en las variedades estudiadas durante cada ciclo agrícola. Medias con una letra común no son significativamente diferentes ( $\mathrm{p}<=0,05)$.

\begin{tabular}{|c|l|c|c|c|c|c|}
\hline Tipo de picadura & Campaña & Daisy & Frital & Innovator & Russet & Shepody \\
\hline Picaduras de Alimentación & $2008 / 2009$ & $\mathrm{c} 0,8$ & $\mathrm{a} 3,4$ & $\mathrm{~b} 2,5$ & $\mathrm{c} 1,2$ & $\mathrm{a} 3,6$ \\
\cline { 2 - 7 } & $2009 / 2010$ & $\mathrm{~b} 0,8$ & $\mathrm{a} 2,5$ & $\mathrm{a} 2,4$ & $\mathrm{~b} 1,1$ & $\mathrm{a} 2,3$ \\
\hline \multirow{2}{*}{ Picaduras de Oviposición } & $2008 / 2009$ & $\mathrm{~b} 0,1$ & $\mathrm{a} 0,3$ & $\mathrm{a} 0,2$ & $\mathrm{a} 0,2$ & $\mathrm{a} 0,3$ \\
\cline { 2 - 7 } & $2009 / 2010$ & $\mathrm{~b} 0,0$ & $\mathrm{a} 0,1$ & $\mathrm{a} 0,1$ & $\mathrm{~b} 0,0$ & $\mathrm{a} 0,2$ \\
\hline
\end{tabular}

En cuanto al número de picaduras de oviposición, la variedad Daisy se diferenció claramente del resto de las variedades presentando, en los dos ciclos agrícolas, el menor número. Las variedades Shepody, Innovator y Frital fueron las que mayor número de picaduras de oviposición presentaron durante los dos ciclos agrícolas. La variedad Russet tuvo un comportamiento intermedio, ya que durante el primer ciclo no se diferenció del grupo de variedades con mayor número de picaduras de oviposición, mientras que durante el segundo ciclo no se diferenció del grupo con menor número de picaduras (Tabla 1).

Las variedades Daisy y Russet fueron las menos preferidas por Liriomyza, tanto para alimentarse como para oviponer, en cambio Shepody y Frital fueron las más preferidas; la variedad Innovator se podría catalogar como de preferencia intermedia. Si bien el ensayo se realizó en condiciones confinadas (jaulas de exclusión), ésta diferenciación en grupos de variedades por grado de preferencia se mantuvo, y coincidió con los resultados observados en el monitoreo de campo en el presente estudio y con las evaluaciones de López et al. (2010). En dicho trabajo se evaluó, en ensayos de campo, el grado de daño que presentaron siete variedades comerciales de papa, y describimos dos grupos de variedades con mayor y menor grado de daño. Ante lo expuesto, la preferencia entre variedades puede atribuirse a características estructurales propias de cada variedad. Resultados similares fueron registrados para otras especies hortícolas. Weigand (1990) reportó la preferencia diferencial de Liriomyza entre cultivares de 
garbanzo, siendo los cultivares de hojas más pequeñas evitados por estos dípteros para alimentarse y oviponer. Otras características varietales, como la distribución, densidad y exudados de tricomas afectan la selección de Liriomyza (Wei et al., 2000). Consecuentemente, alguna de las características antes descriptas podrían condicionar las preferencias de Liriomyza a través de las diferentes variedades de papa estudiadas.

En cuanto a la estratificación del número de picaduras de alimentación, se observó claramente como el estrato basal es el que mayor número de picaduras presentó en todas las variedades y durante los dos ciclos agrícolas. A su vez, el estrato superior fue el que menor número de picaduras presentó en todas las variedades, en ambos ciclos agrícolas. El estrato medio presentó un comportamiento intermedio dificultando su definición dentro de determinado grupo, ya que en algunos casos no se diferenció del estrato basal (con mayor número de picaduras) y en otros no se diferenció del estrato superior (con el menor número de picaduras) (Tabla 2).

Tabla 2. Número de picaduras de alimentación y oviposición por $\mathrm{cm}^{2}$ en pruebas sin elección a campo (promedio de cada estrato) en las variedades estudiadas durante cada ciclo agrícola. ES: Estrato Superior, EM: Estrato Medio, EB: Estrato Basal. Medias con una letra común no son significativamente diferentes $(\mathrm{p}<=0,05)$.

\begin{tabular}{|c|c|c|c|c|c|c|c|}
\hline Tipo de picadura & Campaña & Estrato & Daisy & Frital & Innovator & Russet & Shepody \\
\hline \multirow{6}{*}{$\begin{array}{l}\text { Picaduras de } \\
\text { alimentación }\end{array}$} & \multirow[t]{3}{*}{$2008 / 2009$} & ES & $\mathrm{b} 0,2$ & $\mathrm{~b} 2,1$ & $\mathrm{c} 0,4$ & b1,1 & $\mathrm{b} 2,0$ \\
\hline & & EM & $\mathrm{b} 0,4$ & $\mathrm{a} 4,2$ & $\mathrm{~b} 2,6$ & $\mathrm{~b} 1,1$ & $\mathrm{a} 4,0$ \\
\hline & & EB & $\mathrm{a} 1,8$ & $\mathrm{a} 3,8$ & $\mathrm{a} 4,6$ & a1,3 & $\mathrm{a} 4,7$ \\
\hline & \multirow[t]{3}{*}{$2009 / 2010$} & ES & $\mathrm{c} 0,1$ & $\mathrm{c} 1,2$ & $\mathrm{~b} 1,1$ & $\mathrm{c} 0,3$ & $\mathrm{c} 1,1$ \\
\hline & & EM & $\mathrm{b} 0,7$ & $\mathrm{~b} 2,3$ & $\mathrm{~b} 2,0$ & $\mathrm{~b} 1,2$ & $\mathrm{~b} 2,0$ \\
\hline & & EB & a1,7 & $\mathrm{a} 4,0$ & $\mathrm{a} 4,2$ & $\mathrm{a} 1,8$ & $\mathrm{a} 3,8$ \\
\hline \multirow{6}{*}{$\begin{array}{l}\text { Picaduras de } \\
\text { oviposición }\end{array}$} & \multirow[t]{3}{*}{$2008 / 2009$} & ES & $\mathrm{b} 0,0$ & b0,1 & $\mathrm{b} 0,1$ & $\mathrm{~b} 0,1$ & $\mathrm{~b} 0,1$ \\
\hline & & EM & $\mathrm{b} 0,0$ & $\mathrm{~b} 0,2$ & $\mathrm{~b} 0,1$ & $\mathrm{a} 0,2$ & $\mathrm{~b} 0,2$ \\
\hline & & EB & $\mathrm{a} 0,3$ & $\mathrm{a} 0,4$ & $\mathrm{a} 0,3$ & $\mathrm{a} 0,3$ & $\mathrm{a} 0,4$ \\
\hline & \multirow[t]{3}{*}{$2009 / 2010$} & ES & $\mathrm{b} 0,0$ & $\mathrm{~b} 0,0$ & $\mathrm{~b} 0,0$ & $\mathrm{~b} 0,0$ & $\mathrm{~b} 0$ \\
\hline & & EM & $\mathrm{b} 0,0$ & $\mathrm{a} 0,1$ & $\mathrm{~b} 0,1$ & $\mathrm{~b} 0,0$ & $\mathrm{~b} 0,1$ \\
\hline & & $\overline{E B}$ & $\mathrm{a} 0,1$ & $\mathrm{a} 0,2$ & $\mathrm{a} 0,3$ & $\mathrm{a} 0,1$ & $\mathrm{a} 0,4$ \\
\hline
\end{tabular}

En cuanto al número de picaduras de oviposición entre estratos, se observó una clara estratificación del mismo. El estrato basal presentó el mayor número y el estrato superior el menor número. En cuanto al estrato medio su comportamiento fue similar al del estrato superior, del cual se diferenció significativamente sólo en una oportunidad durante cada ciclo agrícola (Tabla 2).

En cuanto al número de picaduras se observó una clara estratificación, siendo el estrato basal el más preferido tanto para alimentarse como para oviponer, en cambio el estrato superior fue el menos preferido. Esta estratificación puede tener varias causas en condiciones naturales, pero teniendo en cuenta que este ensayo se realizó en el campo, con la plaga confinada en jaulas de exclusión, que la mantuvieron aislada de sus enemigos naturales y de otros organismos fitófagos, se podría suponer que los únicos efectos que estarían determinando esta estratificación serían las características alimenticias de cada estrato del cultivo (tamaño y espesor de los folíolos) y el microambiente de cada estrato. En estas condiciones el estrato inferior ofrecería mejor calidad alimenticia, y además su microambiente seria más fresco y 
húmedo en comparación al estrato superior. Trabajos previos han explorado el efecto de factores climáticos sobre minadores. Parrella y Bethke (1984) evaluaron el efecto de temperaturas constantes $\left(15.6,21.1,26.7,32.2\right.$ y $\left.37.8^{\circ} \mathrm{C}\right)$ sobre la oviposición, alimentación y longevidad de L. trifolii en crisantemo, y concluyeron que la oviposición fue similar a 21.1, 26.7 y $32.2{ }^{\circ} \mathrm{C}$, pero fue significativamente reducida a 15.6 y $37.8{ }^{\circ} \mathrm{C}$, lo que confirma el efecto de la temperatura. En otros estudios se evaluaron la actividad de los adultos de Liriomyza ante diferentes intensidades solares y temperaturas, y se concluyó que con luminosidades superiores a $1,0 \mathrm{~mW} / \mathrm{cm}^{2}$ y temperaturas superiores a $25^{\circ} \mathrm{C}$, los individuos tienden a quedarse protegidos en el envés de las hojas, en cambio cuando la luminosidad se encuentra entre $0,9-11 \mathrm{~mW} / \mathrm{cm}^{2}$ y la temperatura entre 20 a $25^{\circ} \mathrm{C}$ se produce la mayor actividad de los adultos, los cuales se encuentran sobrevolando el cultivo (Chandler y Gilstrap, 1987; Gómez y Rodríguez, 1995). Lo expuesto explica porque los adultos prefieren el estrato basal para alimentarse y oviponer, independientemente de la variedad, ya que este les brindaría un ambiente fresco y protegido de la acción solar.

\section{Efectos de la experiencia previa sobre la preferencia}

Al analizar la experiencia previa de Liriomyza como un factor que puede incidir sobre la preferencia alimentaria y de oviposición, se pudo observar una tendencia similar a la de los ensayos de campo previamente descriptos. Daisy y Russet fueron las variedades menos preferidas para alimentarse durante los dos ciclos agrícolas, y sobre los dos cultivos comerciales analizados (correspondiendo uno de ellos a la variedad Innovator y otro a la variedad Spunta). Las variedades Shepody y Frital fueron las más preferidas para alimentarse; Innovator mostró un comportamiento similar a estas variedades, diferenciándose solo de la variedad Frital, durante el primer ciclo agrícola y en el cultivo comercial de la variedad Spunta. La variedad Innovator siempre estuvo dentro del grupo de las variedades más preferidas cuando se realizaron las evaluaciones sobre los lotes comerciales de la misma variedad (Figura 5 y 6 ).

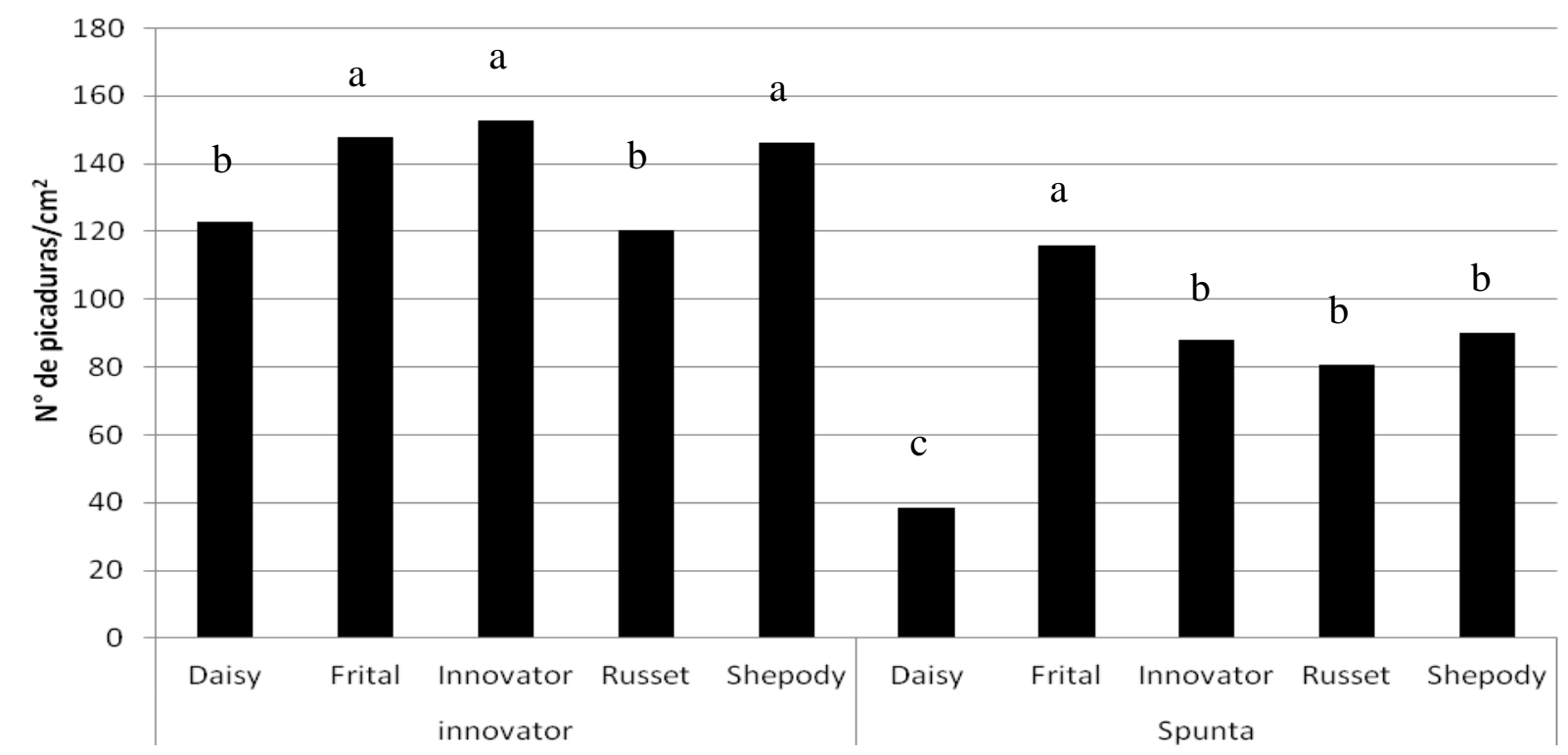

Figura 5. Número de picaduras de alimentación (promedio de todo el canopeo) para cada variedad analizada, durante el ciclo agrícola 2008/2009 sobre cultivos comerciales de las variedades Innovator y Spunta. Medias con una letra común no son significativamente diferentes $(\mathrm{p}<=0,05)$. 


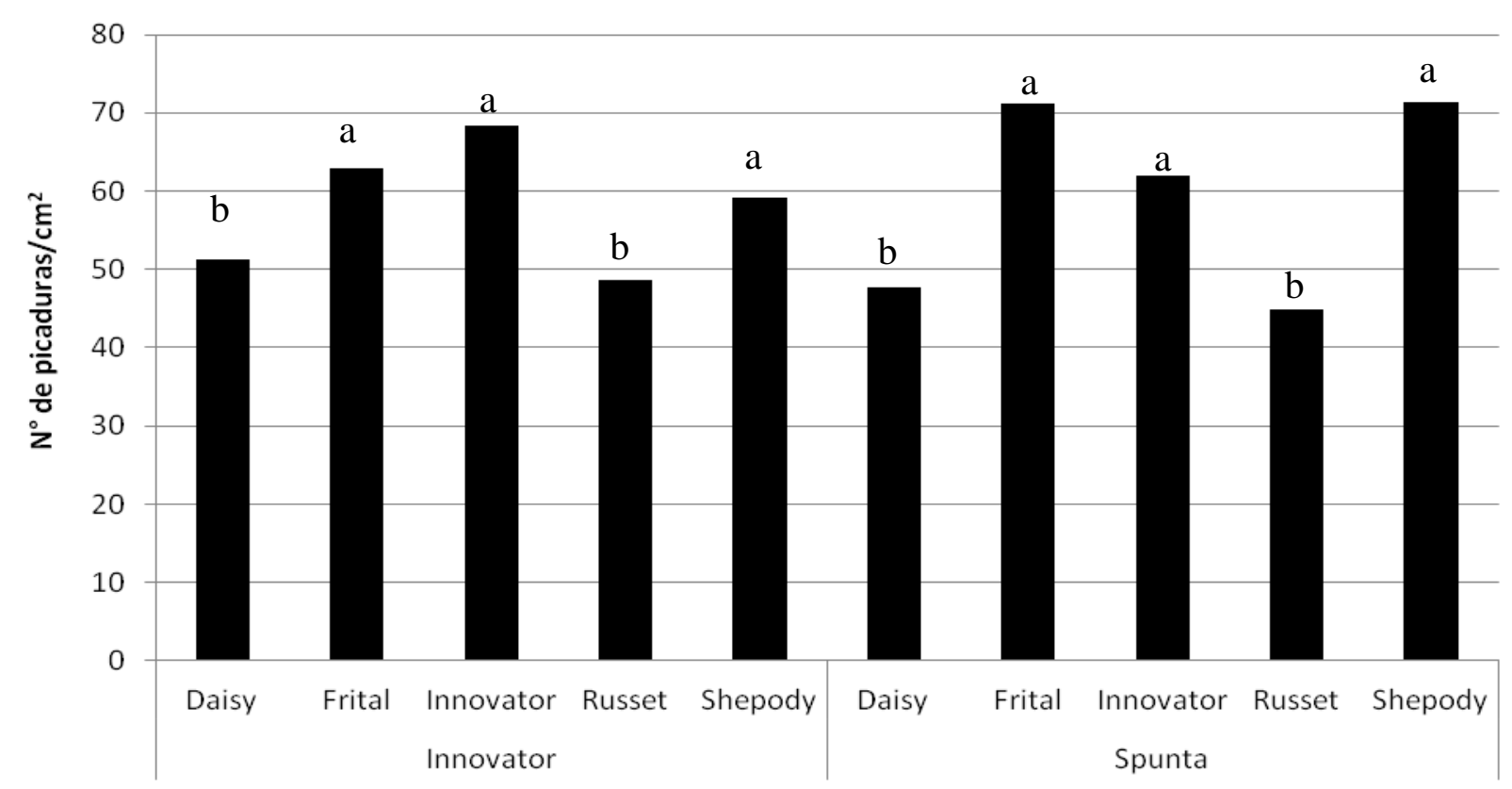

Figura 6. Número de picaduras de alimentación (promedio de todo el canopeo) para cada variedad analizada, durante el ciclo agrícola 2009/2010 sobre cultivos comerciales de las variedades Innovator y Spunta. Medias con una letra común no son significativamente diferentes $(\mathrm{p}<=0,05)$.

En cuanto a las picaduras de oviposición durante el primer ciclo agrícola solo la variedad Daisy presentó un número significativamente menor de picaduras con respecto al resto de las variedades. En el segundo ciclo agrícola las variedades que presentaron menor número de picaduras fueron Daisy, Russet e Innovator, mientras que Shepody y Frital presentaron el mayor número de picaduras, durante los dos ciclos agrícolas, sobre los cultivos comerciales de Innovator y Spunta.

Si bien la tendencia general de preferencia, tanto alimentaria como de oviposición, fue similar a los ensayos de preferencia de campo desarrollados en el primer punto, se pudo observar que en el ensayo dispuesto sobre el cultivo comercial de la variedad Innovator, las plantas evaluadas con esta misma variedad fueron siempre las que mayor picaduras de alimentación y de oviposición presentaron, lo cual demostraría que la experiencia previa es otro factor que podría estar influyendo en las preferencias alimentarias y de oviposición de Liriomyza (Figura 7 y 8). 


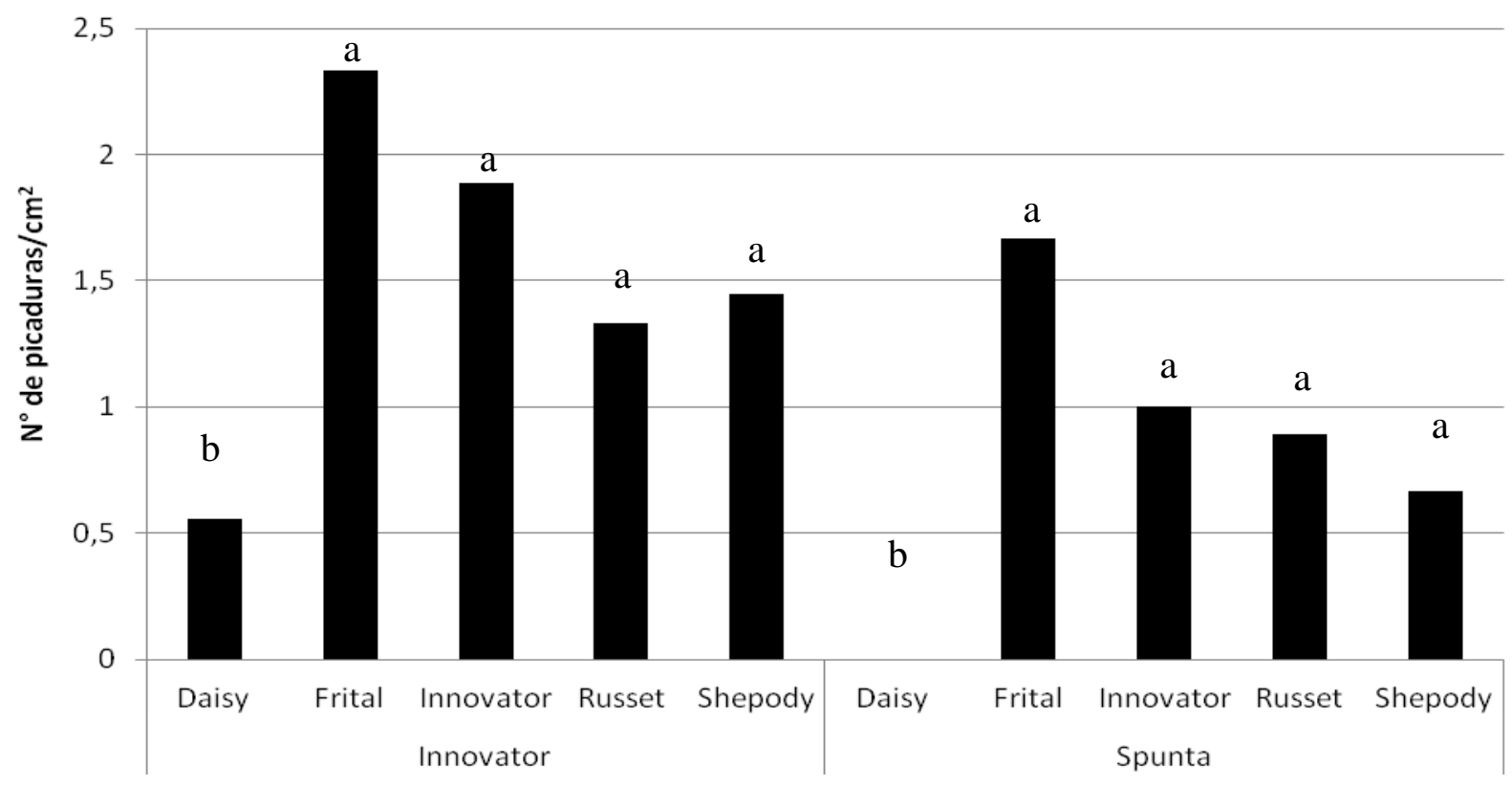

Figura 7. Número de picaduras de oviposición (promedio de todo el canopeo) para cada variedad analizada, durante el ciclo agrícola 2008/2009 sobre cultivos comerciales de las variedades Innovator y Spunta. Medias con una letra común no son significativamente diferentes $(\mathrm{p}<=0,05)$.

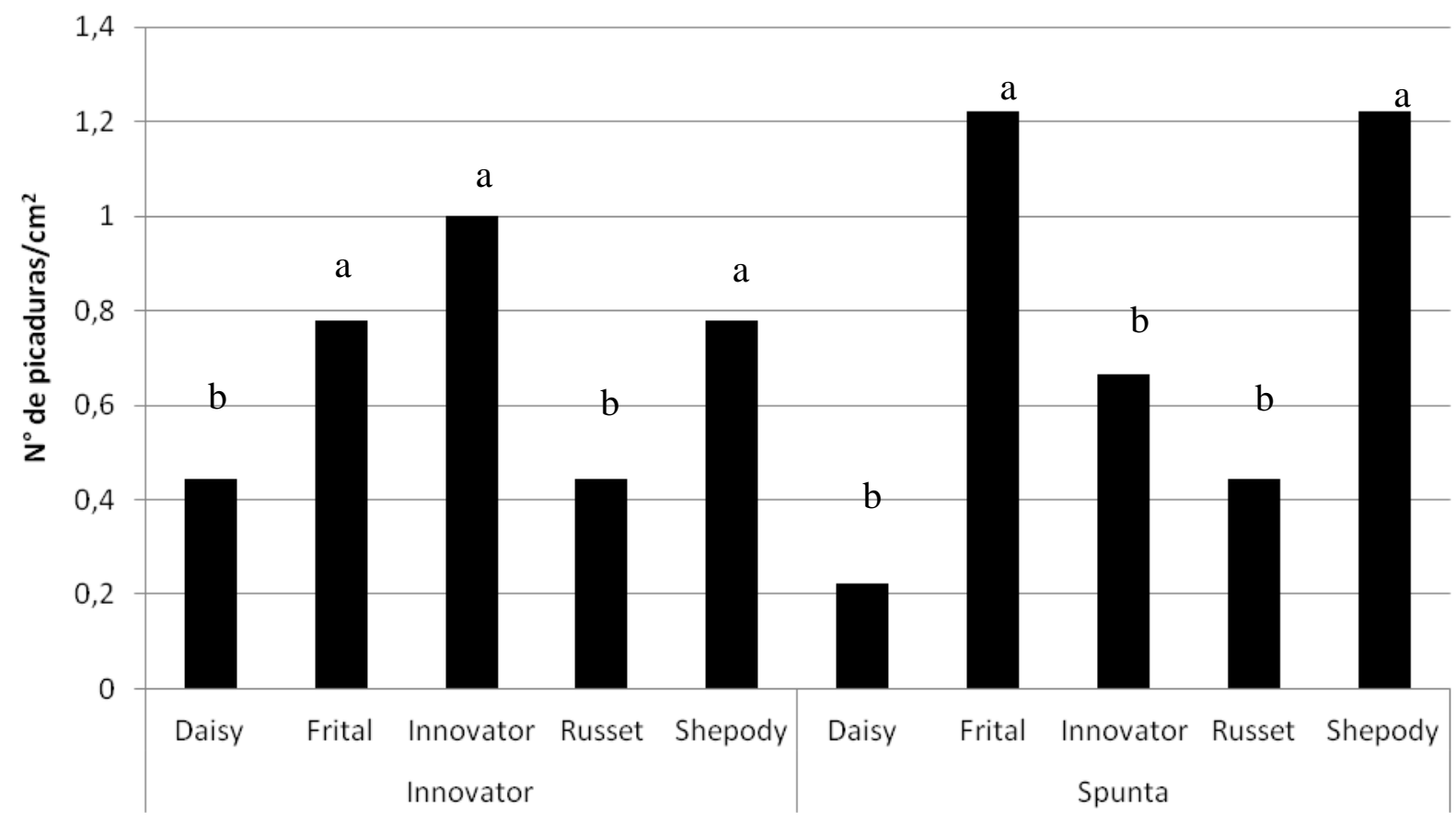

Figura 8. Número de picaduras de oviposición (promedio de todo el canopeo) para cada variedad analizada, durante el ciclo agrícola 2009/2010 sobre cultivos comerciales de las variedades Innovator y Spunta. Medias con una letra común no son significativamente diferentes $(\mathrm{p}<=0,05)$.

Algunos autores postulan que la experiencia previa obtenida por los estados inmaduros en una determinada especie vegetal, podría quedar almacenada en el sistema nervioso central y ser transferida posteriormente al adulto durante la 
metamorfosis (Bernays y Chapman, 1994; Rietdorf y Steidle, 2002). Otros autores proponen que la preferencia del adulto por una especie es adquirida en el breve período que transcurre después de la emergencia, cuando se vería estimulado por los restos vegetales que pudieran quedar en el pupario (Barron, 2001). Las teorías antes descriptas, coinciden con los resultados obtenidos en el presente estudio, y explicarían las razones por la cuales la variedad Innovator fue la más preferida para alimentarse y oviponer, cuando las evaluaciones se realizaron sobre cultivos comerciales de la misma variedad. Quizás deban realizarse estudios bajo condiciones controladas (en laboratorio) para confirmar las tendencias observadas en el presente estudio.

\section{Test de preferencia en el Laboratorio.}

El número de picaduras de alimentación fue mayor en las variedades Shepody e Innovator durante ambos años de evaluación, en cambio las variedades Daisy y Russet fueron las que presentaron el menor número de picaduras de alimentación. La variedad Frital mostró un comportamiento diferencial entre los años de estudio, ya que durante el primer año no se diferenció significativamente del grupo de variedades con menor número de picaduras, y durante el segundo año no se diferenció significativamente del grupo con mayor número de picaduras (Tabla 3).

Tabla 3. Número de picaduras de alimentación y oviposición bajo condiciones controladas (promedio de toda la planta) en las variedades evaluadas durante cada ciclo agrícola. Medias con una letra común no son significativamente diferentes $(\mathrm{p}<=0,05)$.

\begin{tabular}{|c|c|c|c|c|c|c|}
\hline Tipo de picadura & Campaña & Daisy & Frital & Innovator & Russet & Shepody \\
\hline \multirow{2}{*}{ Picaduras de Alimentación } & $2008 / 2009$ & $\mathrm{~b} 1.7$ & $\mathrm{~b} 1.9$ & $\mathrm{a} 2.4$ & $\mathrm{~b} 1.8$ & $\mathrm{a} 2.2$ \\
\cline { 2 - 7 } & $2009 / 2010$ & $\mathrm{~b} 0.8$ & $\mathrm{a} 1.6$ & $\mathrm{a} 1.6$ & $\mathrm{~b} 0.9$ & $\mathrm{a} 1.9$ \\
\hline \multirow{2}{*}{ Picaduras de Oviposición } & $2008 / 2009$ & $\mathrm{~b} 0.1$ & $\mathrm{~b} 0.1$ & $\mathrm{a} 0.2$ & $\mathrm{a} 0.3$ & $\mathrm{a} 0.2$ \\
\cline { 2 - 7 } & $2009 / 2010$ & $\mathrm{~b} 0.1$ & $\mathrm{a} 0.3$ & $\mathrm{~b} 0.2$ & $\mathrm{~b} 0.1$ & $\mathrm{a} 0.3$ \\
\hline
\end{tabular}

Las variedades Daisy y Frital, fueron las que menor número de picaduras de oviposición presentaron durante el primer año de evaluación. En cambio en el segundo año las variedades con menor número de picaduras de oviposición fueron Daisy, Innovator y Russet. La variedad Shepody fue durante los dos años la que mayor número de picaduras de oviposición presentó (Tabla 3).

La preferencia por las diferentes variedades mostró la misma tendencia que en los ensayos de campo, identificándose un grupo de variedades menos preferidas para alimentarse $y$ oviponer formado siempre por la variedad Daisy, y en algunos años las variedades Russet, Innovator y Frital. Otro grupo sería el de las variedades más preferidas para alimentarse y oviponer, está formado siempre por la variedad Shepody y en algunos casos las variedades Russet, Innovator y Frital. Las tres últimas variedades tendrían una preferencia intermedia entre el grupo de las más y menos preferidas. Los resultados descriptos muestran que bajo condiciones controladas L. huidobrensis no es tan selectiva entre variedades, con lo cual los factores externos a las variedades (enemigos naturales, individuos conespecíficos) influyen al momento de seleccionar una variedad para oviponer o alimentarse (Wallin y Raffa, 2004; Eber, 2004). Es importante destacar que al comparar estas pruebas realizadas en laboratorio contra las realizadas en el campo, no solamente se comparo variaciones en el ambiente que se alimenta 
la plaga, sino que además los periodos de cada evaluación son muy diferentes.

En cuanto al número de picaduras de alimentación entre estratos, se puede observar que el estrato basal mostró un número de picaduras similar y en algunos casos menor y en otros mayor con respecto al estrato superior, con lo cual no se puede definir una clara estratificación en cuanto al número de picaduras de alimentación en condiciones controladas durante los dos ciclos de estudio (Tabla 4).

Tabla 4. Número de picaduras de alimentación y oviposición bajo condiciones controladas (promedio de cada estrato) en las variedades estudiadas durante cada ciclo agrícola. ES: Estrato Superior, EM: Estrato Medio, EB: Estrato Basal. Medias con una letra común no son significativamente diferentes $(\mathrm{p}<=0,05)$.

\begin{tabular}{|c|c|c|c|c|c|c|c|}
\hline Tipo de picadura & Campaña & Estrato & Daisy & Frital & Innovator & Russet & Shepody \\
\hline \multirow{6}{*}{$\begin{array}{l}\text { Picaduras de } \\
\text { alimentación }\end{array}$} & \multirow{3}{*}{$2008 / 2009$} & EB & $\mathrm{a} 2,0$ & b1.8 & a2.6 & b1.7 & $\mathrm{a} 2,7$ \\
\hline & & EM & b1.2 & b1.7 & b2.2 & b1.7 & a2.2 \\
\hline & & ES & a1.9 & a2.3 & a2.4 & $\mathrm{a} 2,0$ & b1.8 \\
\hline & \multirow{3}{*}{$2009 / 2010$} & EB & $\mathrm{a} 1,0$ & a1.9 & $\mathrm{a} 1.8$ & $\mathrm{a} 1,0$ & $\mathrm{a} 2.1$ \\
\hline & & EM & b0.7 & b1.6 & b1.3 & b0.7 & b1.8 \\
\hline & & $\overline{E S}$ & b0.8 & b1.3 & a1.6 & $\mathrm{a} 0.9$ & b1.7 \\
\hline \multirow{6}{*}{ Picaduras de oviposición } & \multirow{3}{*}{$2008 / 2009$} & EB & $\mathrm{a} 0.1$ & $\mathrm{a} 0.2$ & $\mathrm{a} 0.3$ & $\mathrm{a} 0.3$ & $\mathrm{a} 0.2$ \\
\hline & & EM & $\mathrm{a} 0.1$ & $\mathrm{a} 0.1$ & $\mathrm{a} 0.2$ & $\mathrm{a} 0.3$ & $\mathrm{a} 0.2$ \\
\hline & & ES & $\mathrm{a} 0.1$ & $\mathrm{~b} 0,0$ & b0.1 & b0.1 & b0.1 \\
\hline & \multirow{3}{*}{$2009 / 2010$} & EB & $\mathrm{a} 0.2$ & $\mathrm{a} 0.3$ & $\mathrm{a} 0.3$ & $\mathrm{a} 0.2$ & $\mathrm{a} 0.3$ \\
\hline & & EM & $\mathrm{a} 0.1$ & $\mathrm{a} 0.3$ & $\mathrm{a} 0.2$ & $\mathrm{a} 0.2$ & $\mathrm{a} 0.3$ \\
\hline & & ES & $\mathrm{b} 0,0$ & $\mathrm{~b} 0.1$ & $\mathrm{~b} 0,0$ & $\mathrm{~b} 0,0$ & b0.1 \\
\hline
\end{tabular}

Al analizar el número de picaduras de oviposición a través de los estratos, se pudo observar que el estrato basal fue siempre el que mayor número de picaduras presentó en ambos años de estudio, mientras que el estrato superior presentó el menor número de picaduras. El estrato medio no se diferenció significativamente del estrato basal, presentando ambos el mayor número de picaduras respecto del estrato superior (Tabla 4).

En condiciones controladas, la estratificación solo se evidenció para las picaduras de oviposición. En el campo la estratificación se registró tanto para picaduras de oviposición como para picaduras de alimentación. Esta diferencia puede deberse a que en condiciones controladas los ambientes son más uniformes a través del canopeo, con lo cual los adultos se alimentan sobre cualquier estrato. En cambio en el campo las condiciones son diferentes entre estratos y los adultos preferirían alimentarse en el estrato basal y medio, donde estarían más protegidos de las altas temperaturas y de la acción directa y desecante del sol. A diferencia de lo antes expuesto la preferencia de oviposición se mantuvo constante, tanto en condiciones de campo como en condiciones controladas, resultando los estratos basal y medio los más preferidos por L. huidobrensis para oviponer. Los resultados descriptos son coincidentes con lo observado por otros autores, que señalan a $L$. huidobrensis como una especie más selectiva para oviponer que para alimentarse (Videla et al., 2006; Verdón et al., 2007). Por lo expuesto, las extrapolaciones de los resultados obtenidos en condiciones controladas a condiciones de campo, deben realizarse con cuidado. En condiciones controladas se simplifica todo el proceso 
de selección, lo cual puede afectar la preferencia real del herbívoro (Singer, 1986).

\section{Conflictos de intereses}

Los autores declaran no tener conflictos con la publicación este trabajo de investigación.

\section{Agradecimientos}

Esta publicación es parte del trabajo de tesis doctoral del primer autor, correspondiente al Posgrado en Ciencias Agrarias, Facultad de Ciencias Agrarias, Universidad Nacional de Mar del Plata, y fue financiada por los proyectos: PNHFA 1106074 INTA, Bases para la Sostenibilidad de las Cadenas de la Papa y la Batata; y Manejo del Agroecosistema y el Paisaje Circundante, para la Regulación Natural de Plagas, en la Produccion Sustentable de Hortalizas, Cereales y Oleaginosas del Sudeste Bonaerense. FCA, Universidad Nacional de Mar del Plata.

\section{Referencias citadas}

Avalos, S. D.; Ricobelli G.; Palacios S. M.; Defago M. T. 2013. Evaluación de la preferencia de Liriomyza spp. en genotipos diferentes de garbanzo y efecto del extracto de Melia azedarach: resultados preliminares. Rev. FCA UNCUYO. 45 (2): $65-73$

Barron, A.B. 2001. The life and death of Hopkins' host-selection principle. J. Ins. Beh. 14: 725-737.

Bernays, E. A.; Chapman, R. F. 1994. Host-plant selection by phytophagous insects. New York: Chapman \& Hall, 312 pp.

Boller, E.F.; Katsoyannos, B.I.; hippe, C. 1998. Host races of Rhagoletis cerasi L. (Dipt., Tephritidae): Effect of prior adult experience on oviposition site preference. J. Appl. Ento. 122: 231-237.

Cambareri, S. 2004. Fluctuación poblacional de L. huidobrensis Blanchard y su incidencia en cultivos de papa del sudeste bonaerense. Tesis de Grado, Facultad de Ciencias Agrarias, Universidad Nacional de Mar del Plata, Arg. 58 p.

Carmona, D.; Caldiz, D. 2003. Manejo integrado del cultivo: biología y control de la "mosca minadora de la hoja". Del campo a la fábrica 3 (2): 6.

Carmona, D.; López, R. 2007. Bioecología y Manejo Integrado de la "mosca minadora de las hojas" Liriomyza huidobrensis (Blanchard) (Diptera: Agromyzidae). En: $5^{\circ}$ Curso Internacional de Producción de Papa Semilla (Balcarce, 2007, mar 17-25). INTA, Balcarce, Argentina. 14 p.

Chandler, L. D.; Gilstrap, F. E. 1987. Seasonal fluctuations and age structure of Liriomyza trifolii (Diptera: Agromyzidae) larval populations on bell peppers. Journal of Economic Entomology. 80: 102-106.

Di Rienzo, J.A.; Casanoves, F.; Balzarini, M.G.; Gonzalez, L.; Tablada, M.; Robledo, C.W. InfoStat versión 2013. Grupo InfoStat, FCA, Universidad Nacional de Córdoba, Argentina. URL http://www.infostat.com.ar

Eber, S. 2004. Bottom-up density regulation in the holly leaf-miner Phytomyza ilicis. J. An. Eco. 73: 948-958.

Facknath, S. 2005. Leaf age and leaf history variables of the leafminer: the case of Liriomyza trifolii on potato leaves. Ento. Exp. Appl. 115:79-87.

Faeth, S. 1985. Host leaf selection by leafminer: interactions among three trophic levels. Ecology 66: 870-875.

Fagoonee, I.; Toory, V. 1983. Preliminary investigations of host selection mechanisms by the leafminer Liriomyza trifolii. Ins. Sci. Appl. 4: 337-341.

Fisher, A. E. I.; Hartley, S. E.; Young, M. 2000. Direct and indirect competitive effects of foliage feeding guildson the performance of the birch leaf-miner Eriocrania. J. An. Eco. 69: 165-176. 
Gómez, B.Y.; Rodríguez, V.C.L. 1994. Capture of adults of Liriomyza huidobrensis (Blanchard) with yellow traps and its relation to damage to potato (Solanum tuberosum) plants. Manejo Integrado de Plagas 33: 19-22.

Gómez, Y.; Rodríguez, C. 1995. Actividad de Liriomyza huidobrensis de acuerdo a las diversas horas del día y tipos de muestreo en relación a la fenología del cultivo de papa (Solanum tuberosum). Agronomía Mesoamericana. 6: 32-49.

Kimmerer, T. W.; Potter, D. A. 1987. Nutritional quality of specific leaf tissues and selective feeding by a specialist leafminer. Oecologia 71: 548-551.

Li, Y.; Xi, D.W.; Wei, X. 2003. On the selection behavior and Mechanism of Liriomyza sativae (Blanchard) in choosing tomato Varieties. Acta Phytophylacica Sinica 30: 25-29.

López, R. 2008. Determinación del nivel de daño económico de la "mosca minadora de la hoja" Liriomiza huidobrensis Blanchard en dos variedades de papa para industria. Tesis MSc, Facultad de Ciencias Agrarias, Universidad Nacional de Mar del Plata, Arg. 67 p.

López, R.; Carmona, D.; Vincini, A. M.; Monterubbianesi, G.; Caldiz, D. 2010. Population dynamic and damage caused by the Leafminer Liriomyza huidobrensis (Blanchard: Agromyzidae), on seven potato processing varieties grown in températe environment. Neotro. Ento. 39 (1): 108-114.

Martin A. D., D. Stanley-Horn, R. H. Hallett. 2005. Adult host preference and larval performance of Liriomyza huidobrensis (Diptera: Agromyzidae) on selected hosts. Envir. Ento. 34(5): 11701177.

Mcneely, C.; Singer, M.C. 2001. Contrasting the roles of learning in butterflies foraging for nectar and oviposition sites. An. Behaviour 61: 847852.
Neder De Roman, L.E.; Arce De Hamity, M.G.; Quincoces De Guerra, V. 1993. Invasion mechanism of Liriomyza huidobrensis (Blanchard) (Diptera: Agromyzidae) on Vicia faba crop. IDESIA 12: 25-29.

Parrella, P; Bethke, J. 1984. Biological studies of Liriomyza huidobrensis (Diptera: Agromyzidae) on Chrisantemum, Aster and Pea. J. Econ. Ento. 77: 342-345.

Rietdorf, K.; Steidle, J.L.M. 2002. Was hopkins right? Influence of larval and early adult experience on the olfactory response in the granary weevil Sitophilus granaries (Coleoptera, Curculionidae). Phys. Ento. 27: 223-227.

Singer, M.C. 1986. The definition and measurement of oviposition preference in plantfeeding insects. in: Miller Jr, Miller T. A.a, editors. Insect-Plant interactions. New York: Springer-Verlag; pp 65-84.

Solarz, S.L.; Newman, R.M. 2001. Variation in hostplant preference and performance by the milfoil weevil, Euhrychiopsis lecontei Dietz, exposed to native and exotic watermilfoils. Oecologia 126: 66-75.

Suomela, J.; Nilson, A. 1994. Within-tree and among-tree variation in growth of Epirrita autumnata on mountain birch leaves. Eco. Ento. 19: 45-56.

Valladares, G.; Pinta, D.; Salvo, A. 1996. La mosca minadora (Liriomyza huidobrensis Blanchard) en cultivos hortícolas de Córdoba. Hort. Arg. 15 (39): 13-18.

Verdon, A.; Margraf, N.; Davison, A.C.; Rahier, M.; Naisbit, R.E. 2007. Conserved oviposition preferences in alpine leaf beetle populations despite host shifts and isolation. Eco. Ento. 32: 62-69.

Videla, M.; Valladares, G.; Salvo, A. 2006. A tritrophic analysis of host preference and performance in a polyphagous leafminer. Ento. Exp. Appl. 121: 105-14. 
Vincini, A. M.; Carmona, D. 2006. Manejo Integrado de los factores y procesos que reducen el rendimiento: Insectos. En: D. Caldiz ed Producción, cosecha y almacenamiento de papa en la Argentina. McCain, Basf, Luba, Buenos Aires, Argentina. pp. 165-168.

Wallin, K.F.; Raffa, K.F. 2004. Feedback between individual host selection behavior and population dynamics in an eruptive herbivore. Eco. Monographs 74: 101-116.

Wei, J.; Zou, L.; Kuang, R.; He, L. 2000. Influence of leaf tissues on host feeding selection by pea leafminer Liriomyza huidobrensis (Diptera: Agromyzidae). Zool. Studies. 39: 295-300.

Weigand, S. 1990. Insect pests of chickpea in the Mediterranean area and possibilities for resistance. Options Méditerranéennes. Série Séminaires: 9: 73-76.

Weintraub, P.; Horowitz, R. 1995. The newest leafminer pest in Israel, Liriomyza huidobrensis. Phytoparasitica 23 (2): 177184. 